\title{
BMJ Open Mid-upper arm circumference, calf circumference and mortality in Chinese long-term care facility residents: a prospective cohort study
}

\author{
Chien-Hsiang Weng, ${ }^{1,2,3}$ Chia-Ping Tien, ${ }^{4}$ Chia-Ing Li, ${ }^{5}$ Abby L'Heureux, ${ }^{6}$ \\ Chiu-Shong Liu, ${ }^{4,7,8}$ Chih-Hsueh Lin, ${ }^{4,8}$ Cheng-Chieh Lin, ${ }^{4,7}$ Shih-Wei Lai, ${ }^{4,8}$ \\ Ming-May Lai, ${ }^{4}$ Wen-Yuan $\operatorname{Lin}^{4,7,8}$
}

To cite: Weng C-H, Tien C-P, Li C-I, et al. Mid-upper arm circumference, calf circumference and mortality in Chinese long-term care facility residents: a prospective cohort study. BMJ Open 2018;8:e020485. doi:10.1136/ bmjopen-2017-020485

- Prepublication history for this paper is available online. To view these files, please visit the journal online (http://dx.doi. org/10.1136/bmjopen-2017020485).

C-HW and C-PT share first authorship.

Received 6 November 2017 Revised 24 February 2018 Accepted 4 April 2018
Check for updates

For numbered affiliations see end of article.

Correspondence to

Prof. Wen-Yuan Lin;

wylin@mail.cmu.edu.tw

\section{ABSTRACT}

Objective To investigate the association between midupper arm circumference (MUAC), calf circumference (CC) and all-cause mortality in a Chinese population.

Design Prospective cohort study.

Setting Eight long-term care facilities in central Taiwan. Participants A total of 329 residents age 60 years and older (median 79.0 years, range 60-101; 139 men, 190 women) were enrolled.

Methods Anthropometrics and metabolic parameters were measured at the time of enrolment to the study. Mean MUAC and CC were $24.2 \pm 3.4 \mathrm{~cm}$ and $27.5 \pm 4.3 \mathrm{~cm}$, respectively. Mortality data were obtained from the Department of Health in Taiwan.

Main outcome measure To identify the association between all-cause mortality and MUAC or CC.

Results There were 255 deaths during the 7 -year followup period. After adjusting for age, sex, cigarette smoking, betel nut chewing, alcohol use, Karnofsky Performance Status Scale score, serum albumin level, hypertension and diabetes mellitus, subjects in the highest tertile of MUAC $(27.8 \pm 2.2 \mathrm{~cm})$ and $\mathrm{CC}(32.1 \pm 2.6 \mathrm{~cm})$ had a significantly lower mortality rate than did subjects in the lowest tertile (MUAC 20.6 $\pm 1.7 \mathrm{~cm}$; CC $22.8 \pm 1.9 \mathrm{~cm}$ ). The adjusted HR for all-cause mortality in the highest versus lowest MUAC tertile was 0.64 (95\% $\mathrm{Cl} 0.45$ to 0.90). The adjusted HR for all-cause mortality in the highest versus lowest CC tertile was 0.51 (95\% Cl 0.35 to 0.74$)$.

Conclusions MUAC and CC are negative predictors for all-cause mortality in older Chinese adults living in longterm care facilities. Participants with higher MUAC and CC had lower all-cause mortality.

\section{INTRODUCTION}

According to the WHO, both the number and proportion of the older adult population, defined as age 60 years and older, are growing in virtually all countries, and this worldwide trend is likely to continue unabated. It is estimated that by 2025 , the size of the older adult population worldwide will reach more than 1.2 billion. ${ }^{1}$ The growing proportion of older adults leads to the growing demand for long-term care. ${ }^{2}$
Strengths and limitations of this study

- This prospective cohort study included eight longterm care facilities in central Taiwan to investigate the association of mid-upper arm circumference (MUAC), calf circumference (CC) and all-cause mortality.

- The study is based on a nationally representative sample with a relatively large sample size; thus, the results from our analysis should be generalisable to the Chinese population as a whole.

- However, since the participants were residents of long-term care facilities, caution should be used when generalising the results to the community-dwelling population, indigenous Taiwanese or the rural population.

Previous studies have reported a U-shaped association between body mass index (BMI) and all-cause mortality, revealing a higher BMI may be associated with lower all-cause mortality in the older adult. ${ }^{34}$ The relationship between waist circumference (WC) and all-cause mortality seems to be debatable. Our previous study found that BMI and WC were both negative predictors for all-cause mortality in older Chinese adults living in long-term care facilities, while a recent Australian study concluded a positive correlation between WC and all-cause mortality. ${ }^{45}$ Unfortunately, due to practical limitations, BMI is not commonly used in the older population. ${ }^{6}$ For frail and ill elders, an individual's height and weight are often inaccurate and difficult to measure. Alternatively, mid-upper arm circumference (MUAC) ${ }^{7-9}$ and calf circumference (CC) $)^{10-12}$ are more often used in geriatric health measurement scales as these are easier anthropometric indicators to obtain. A previous study found that low MUAC and low CC can effectively predict follow-up mortality 
risk in community-based Chinese older adults aged 65-74 years. ${ }^{13}$

Therefore, the aim of this study was to respectively evaluate the relationship between MUAC and CC and all-cause mortality in an older ( $\geq 60$ years) Chinese population living in long-term care facilities in Taiwan.

\section{METHODS}

\section{Study subjects}

In this prospective cohort study, the target population was residents of eight long-term care facilities with the affiliation to China Medical University Hospital, the largest tertiary medical centre in central Taiwan. Long-term care facilities provide a variety of services, both medical and personal care to people who are unable to manage independently in the community and offer residents 24 hours care from nurses with regular physician visits. The location and size of these long-term care facilities loosely correspond to population density in Taiwan, with more, larger facilities near urban centres, and fewer, smaller facilities in rural areas. Characteristics of residents in the facilities are generally representative of the surrounding population as a whole. Thus, our cohort is likely a nationally representative sample. Enrolment took place in 2002-2003. Deaths were ascertained using a database linked to the Taiwanese National Death Registry by individual identification number. All deaths occurring between study entry and December 2009 were included.

\section{Anthropometric index}

Trained staff members measured participants' weight, height, MUAC and CC. MUAC was measured at the midway point between the olecranon process of the ulna and the acromion process of the scapula. CC was measured as the maximum horizontal distance around the left calf as the subject stood upright. ${ }^{14}$ MUAC and CC were divided by sex and into quantitative tertiles (MUAC tertiles I-III: $<22.9,22.9-25.6, \geq 25.7 \mathrm{~cm}$ in men and $<22.8,22.8-25.4, \geq 25.5 \mathrm{~cm}$ in women; CC tertiles IIII: $<26.0,26.0-29.9, \geq 30.0 \mathrm{~cm}$ in men and $<25.0,25.0-$ $28.3, \geq 28.4 \mathrm{~cm}$ in women).

\section{Biomedical markers}

The same group of trained staff members measured participants' blood pressure (BP) in the right arm using an appropriately sized cuff and a standard mercury sphygmomanometer in a seated, resting position. A venous blood sample was taken after a 12 hours fast for the measurement of serum glucose, albumin and lipid profile using a biochemical auto analyzer (Beckman Coulter, Fullerton, California, USA) at the Clinical Laboratory of China Medical University Hospital.

\section{Questionnaire, diabetes mellitus, hypertension and Karnofsky Performance Status Scale (KPSS)}

Age, sex, performance status (as KPSS score), lifestyle (smoking, betel nut chewing and alcohol consumption), nutritional status (as albumin), diabetes mellitus status and hypertension status were identified as potential confounders to our analysis. To determine the value of these variables for each patient, the authors reviewed individual medical records and asked study participants to complete a structured questionnaire. Smoking history was divided into three categories-never, former and current smokers. Diabetes mellitus was defined as fasting glucose of $126 \mathrm{mg} / \mathrm{dL}$ or greater, or a history of diabetes mellitus treated with oral hypoglycaemic agents or insulin injection. Hypertension was defined as systolic blood pressure (BP) of $140 \mathrm{~mm} \mathrm{Hg}$ or greater, diastolic BP of $90 \mathrm{~mm} \mathrm{Hg}$ or greater or a history of hypertension treated with antihypertensive medications. The KPSS is an assessment tool used to assist physicians and caregivers in evaluating a patient's ability to perform daily activities. ${ }^{15}$ On a scale of $0-100$, where 0 indicates death and 100 indicates perfect health, a KPSS score less than 60 is defined as requiring some assistance. ${ }^{15}$

\section{Statistical analysis}

The data were presented as means \pm SD for continuous variables. Log transformation was used for variables with significant deviation from the normal distribution and assessed using the Kolmogorov-Smirnov test before further analyses. Analysis of variance was used to compare mean values of continuous variables across MUAC and CC tertiles. The Student's t-test for unpaired data was used to compare mean values between groups as shown in tables 1 and 2. Proportions and categorical variables were presented as percentages and tested using the $\mathrm{X}^{2}$ test and the two-tailed Fisher exact test when appropriate. Cox proportional hazards regression analyses adjusted for potential confounders were used to estimate the HRs for all-cause mortality. ${ }^{16}$ We analysed the HR of all-cause mortality in different subgroups (tertiles) of MUAC and CC and compared the adjusted and unadjusted HRs. Four models were created for the analysis in order to better examine the effects from different risk factors based on their individual clinical importance.

Model I: Unadjusted HR.

Model II: HR adjusted for age and sex.

Model III: Model II+HR adjusted for smoking status, alcohol use, betel nut chewing and KPSS.

Model IV: Model III+HR adjusted for albumin, hypertension and diabetes.

Kaplan-Meier survival curves based on MUAC and CC tertiles were drawn, and log-rank test was used to test the significance of the survival differences between tertiles by MUAC and CC.

All statistical tests were two-sided at the 0.05 significance level. These statistical analyses were performed using the PC version of SPSS statistical software V.20.

\section{Patient and public involvement}

The development of the research question and outcome measures were based on the experiences from providing clinical care to older patients and felt the need to examine alternative measurements in assessing the association to all-cause mortality. Patients who agreed to enrol to the 
Table 1 Cohort characteristics according to mid-upper arm circumference (MUAC) tertiles

\begin{tabular}{|c|c|c|c|c|}
\hline \multirow[b]{2}{*}{ Characteristics } & \multicolumn{3}{|l|}{ MUAC tertile } & \multirow[b]{2}{*}{$P$ values } \\
\hline & I (n=109) & II $(n=110)$ & III $(n=110)$ & \\
\hline Male, n (\%) & $46(42.2)$ & $46(41.8)$ & $47(42.7)$ & 0.991 \\
\hline Height, cm & $151.8 \pm 7.4$ & $152.1 \pm 8.1$ & $154.1 \pm 7.9$ & 0.069 \\
\hline Weight, kg & $42.4 \pm 6.9$ & $51.0 \pm 9.0$ & $59.2 \pm 9.8$ & $<0.001$ \\
\hline Resting energy expenditure, kcal/d & $930.3 \pm 151.0$ & $1061.5 \pm 188.3$ & $1190.1 \pm 196.0$ & $<0.001$ \\
\hline Waist circumference, $\mathrm{cm}$ & $74.4 \pm 6.8$ & $82.5 \pm 8.6$ & $90.6 \pm 9.8$ & $<0.001$ \\
\hline Mid-upper arm circumference, cm & $20.6 \pm 1.7$ & $24.1 \pm 0.8$ & $27.8 \pm 2.2$ & $<0.001$ \\
\hline Calf circumference, $\mathrm{cm}$ & $24.1 \pm 2.9$ & $27.8 \pm 3.3$ & $30.5 \pm 4.0$ & $<0.001$ \\
\hline Systolic BP, mm Hg & $123.7 \pm 13.9$ & $124.3 \pm 15.1$ & $126.4 \pm 14.6$ & 0.348 \\
\hline Triglycerides, ng/dL & $86.8 \pm 61.1$ & $103.5 \pm 65.0$ & $149.2 \pm 306.4$ & 0.036 \\
\hline High-density lipoprotein cholesterol & $56.8 \pm 15.3$ & $50.4 \pm 13.3$ & $49.4 \pm 10.9$ & $<0.001$ \\
\hline Albumin, g/dL & $3.04 \pm 0.47$ & $3.23 \pm 0.40$ & $3.34 \pm 0.42$ & $<0.001$ \\
\hline $\begin{array}{l}\text { Karnofsky Performance Status Scale score }>60 \%, n \\
(\%)\end{array}$ & $13(12.4)$ & $22(20.6)$ & $33(29.5)$ & 0.008 \\
\hline Diabetes mellitus, $\mathrm{n}(\%)$ & $17(15.6)$ & $40(37.0)$ & $44(39.3)$ & $<0.001$ \\
\hline Hypertension, n (\%) & $55(50.5)$ & $67(62.0)$ & $70(62.5)$ & 0.123 \\
\hline Smoking, n (\%) & & & & 0.187 \\
\hline Current & $1(1.0)$ & $3(2.8)$ & $4(3.6)$ & \\
\hline Alcohol, n (\%) & & & & 0.272 \\
\hline Current & $1(0.9)$ & $1(0.9)$ & $2(1.8)$ & \\
\hline Former & $5(4.7)$ & $13(12.1)$ & $12(10.7)$ & \\
\hline Never & 99 (94.3) & $93(86.9)$ & $98(87.5)$ & \\
\hline
\end{tabular}

The Pearson $\mathrm{X}^{2}$ test was used for categorical data.

Analysis of variance was used for comparing mean values of continuous variables between groups.

Statistics were tested using log-transformed values.

$\mathrm{BP}$, blood pressure.

study received standard care which did not differ from those who declined to enrol. The recruitment process was mentioned in the Study Subject section. The results from this study were not disseminated to the study participants since the purpose of the study was to examine alternative measures in correlation to all-cause mortality.

\section{RESULTS}

A total of 447 residents lived in the eight long-term care facilities. Of these, 393 were of age $\geq 60$ years and were invited to participate in the study. Thirty-nine of them declined. Of the 354 remaining (156 men and
198 women), 25 participants did not have appropriately recorded data for MUAC or CC. Therefore, 329 subjects were retained for our study analysis (139 men, mean age $76.5 \pm 7.6$ years; 190 women, mean age $80.0 \pm 7.6$ years). In the 7-year follow-up period, there were 255 deaths and the total person years at risk was 1159.13. The baseline characteristics of the cohort presented in MUAC and CC tertiles are shown in tables 1 and 2. The higher tertiles of MUAC tended to have heavier weight and higher BMI, WC, CC, total cholesterol, triglycerides, albumin, KPSS score and prevalence of diabetes mellitus, but younger age and lower high-density lipoprotein cholesterol. The 
Table 2 Cohort characteristics according to calf circumference (CC) tertiles

\begin{tabular}{|c|c|c|c|c|}
\hline \multirow[b]{2}{*}{ Characteristics } & \multicolumn{3}{|l|}{ CC tertile } & \multirow[b]{2}{*}{$P$ values } \\
\hline & $I(n=105)$ & II (n=117) & III $(n=107)$ & \\
\hline Male, n (\%) & 45 (42.9) & $50(42.7)$ & $44(41.1)$ & 0.959 \\
\hline Age, year & $80.3 \pm 8.0$ & $79.2 \pm 7.3$ & $76.3 \pm 7.6$ & $<0.001$ \\
\hline Height, cm & $151.6 \pm 7.8$ & $152.2 \pm 7.3$ & $154.3 \pm 8.2$ & 0.030 \\
\hline Weight, kg & $42.2 \pm 7.3$ & $50.5 \pm 8.0$ & $60.3 \pm 9.4$ & $<0.001$ \\
\hline $\mathrm{BMI}, \mathrm{kg} / \mathrm{m}^{2}$ & $18.4 \pm 3.2$ & $21.4 \pm 3.0$ & $25.2 \pm 3.6$ & $<0.001$ \\
\hline Resting energy expenditure, $\mathrm{kcal} / \mathrm{d}$ & $931.3 \pm 158.7$ & $1045.2 \pm 176.7$ & $1205.6 \pm 192.7$ & $<0.001$ \\
\hline Waist circumference, $\mathrm{cm}$ & $75.5 \pm 8.5$ & $81.4 \pm 8.0$ & $90.7 \pm 10.0$ & $<0.001$ \\
\hline Mid-upper arm circumference, $\mathrm{cm}$ & $21.6 \pm 2.8$ & $24.1 \pm 2.3$ & $26.7 \pm 3.0$ & $<0.001$ \\
\hline Calf circumference, $\mathrm{cm}$ & $22.8 \pm 1.9$ & $27.0 \pm 1.3$ & $32.1 \pm 2.6$ & $<0.001$ \\
\hline Systolic BP, mm Hg & $124.8 \pm 13.8$ & $123.5 \pm 14.3$ & $126.2 \pm 15.4$ & 0.386 \\
\hline Diastolic BP, mm Hg & $74.4 \pm 11.1$ & $74.2 \pm 9.0$ & $75.8 \pm 12.2$ & 0.479 \\
\hline Total cholesterol, mg/dL & $170.0 \pm 41.2$ & $173.0 \pm 41.7$ & $184.7 \pm 42.7$ & 0.026 \\
\hline Triglycerides, ng/dL & $90.0 \pm 53.9$ & $101.8 \pm 76.1$ & $149.1 \pm 310.7$ & 0.048 \\
\hline High-density lipoprotein cholesterol & $53.3 \pm 15.0$ & $53.5 \pm 14.5$ & $49.6 \pm 10.7$ & 0.058 \\
\hline Albumin, $\mathrm{g} / \mathrm{dL}$ & $2.96 \pm 0.45$ & $3.25 \pm 0.39$ & $3.40 \pm 0.39$ & $<0.001$ \\
\hline $\begin{array}{l}\text { Karnofsky Performance Status Scale score }>60 \%, n \\
(\%)\end{array}$ & $5(5.0)$ & $17(16.0)$ & $46(39.3)$ & $<0.001$ \\
\hline Diabetes mellitus, $\mathrm{n}(\%)$ & $18(17.1)$ & $39(36.5)$ & $44(37.6)$ & 0.001 \\
\hline Hypertension, n (\%) & $58(55.2)$ & $61(57.0)$ & $73(62.4)$ & 0.526 \\
\hline Smoking, n (\%) & & & & 0.016 \\
\hline Current & $0(0)$ & $4(3.8)$ & $4(3.4)$ & \\
\hline Former & $12(11.9)$ & $11(10.4)$ & $26(22.2)$ & \\
\hline Never & $89(88.1)$ & $91(85.9)$ & $87(74.4)$ & \\
\hline Betel nut, n (\%) & & & & 0.017 \\
\hline Current & $0(0)$ & $0(0)$ & $2(1.7)$ & \\
\hline Former & $2(2.0)$ & $1(0.9)$ & $9(7.7)$ & \\
\hline Never & 99 (98.0) & 105 (99.1) & $106(90.6)$ & \\
\hline Alcohol, n (\%) & & & & 0.150 \\
\hline Current & $0(0)$ & $2(1.9)$ & $2(1.7)$ & \\
\hline Former & $6(6.0)$ & $8(7.6)$ & $16(13.7)$ & \\
\hline Never & 95 (94.0) & $96(90.6)$ & 99 (84.6) & \\
\hline
\end{tabular}

The Pearson $\mathrm{X}^{2}$ test was used for categorical data.

Analysis of variance was used for comparing mean values of continuous variables between groups.

Statistics were tested using log-transformed values.

$\mathrm{BP}$, blood pressure.

higher tertiles of $\mathrm{CC}$ tended to weigh more and have higher BMI, WC, MUAC, total cholesterol, triglycerides, albumin, KPSS score, prevalence of DM, smoking and betel nut chewing, but younger age.

We analysed the HR of all-cause mortality in different subgroups (tertiles) of MUAC and CC and compared the adjusted and unadjusted HRs. All four models demonstrated highest mortality in the lowest tertiles of MUAC and CC (with and without adjustment for confounders) (table 3). We also performed a test for MUAC and CC interaction with age in model II (adjusted for age and sex), and the results were not statistically significant (age and MUAC, $\mathrm{p}=0.4489$; age and $\mathrm{CC}, \mathrm{p}=0.4685$ ). Thus, age was not an effect modifier of mortality in our study.

Using Cox proportional hazards regression analyses, we found that the unadjusted HRs for all-cause mortality were significantly lower in the highest MUAC and CC tertiles (both $\mathrm{p}<0.05$, table 3 ). The adjusted HRs for all-cause mortality were significantly lower in the highest tertile of MUAC and CC than in the lowest tertile (all $\mathrm{p}<0.05$, table 3). Using the lowest tertile of MUAC and $\mathrm{CC}$ as baseline for comparison, the adjusted HRs of the highest tertile of MUAC and CC are 0.64 (95\% CI 0.45 to 0.90 ) and 0.51 (95\% CI 0.35 to 0.74 ), respectively 
Table 3 Risks of all-cause mortality according to MUAC and CC tertiles using Cox proportional hazards regression analyses

\begin{tabular}{|c|c|c|c|c|c|c|}
\hline \multirow[b]{2}{*}{ Tertile (n) } & \multirow{2}{*}{$\begin{array}{l}\text { Deaths } \\
\text { (n) }\end{array}$} & \multirow{2}{*}{$\begin{array}{l}\text { 7-year mortality rate per } \\
1000 \text { person-years }\end{array}$} & \multicolumn{4}{|c|}{ All-cause mortality HR $(95 \% \mathrm{Cl})$} \\
\hline & & & Model I & Model II & Model III & Model IV \\
\hline \multicolumn{7}{|l|}{ MUAC† } \\
\hline II & 84 & 206.91 & $0.62(0.46 \text { to } 0.83)^{\star \star}$ & $0.66(0.49 \text { to } 0.90)^{\star *}$ & 0.74 (0.54 to 1.00$)$ & $0.74(0.54$ to 1.02$)$ \\
\hline III & 75 & 162.40 & $0.48(0.35 \text { to } 0.65)^{\star \star}$ & $0.55(0.40-0.75)^{\star \star}$ & $0.61(0.44-0.85)^{\star \star}$ & $0.64(0.45-0.90)^{\star}$ \\
\hline II & 81 & 205.91 & $0.55(0.41 \text { to } 0.75)^{\star *}$ & $0.56(0.42-0.76)^{\star \star}$ & $0.59(0.43-0.80)^{\star \star}$ & $0.62(0.45-0.86)^{\star \star}$ \\
\hline III & 80 & 158.68 & $0.42(0.31 \text { to } 0.57)^{\star \star}$ & $0.46(0.34-0.62)^{\star \star}$ & $0.49(0.34-0.70)^{\star \star}$ & $0.51(0.35-0.74)^{\star *}$ \\
\hline
\end{tabular}

Model I: unadjusted.

Model II: adjusted for age and sex.

Model III: Model II+adjusted for smoking, alcohol, betel nut and Karnofsky Performance Status Scale.

Model IV: Model III+adjusted for albumin, hypertension and diabetes mellitus.

${ }^{*} \mathrm{P}<0.05 ;{ }^{* *} \mathrm{P}<0.01$.

†MUAC was divided by sex and into quantitative tertiles: $<22.9,22.9-25.6, \geq 25.7 \mathrm{~cm}$ in men; $<22.8,22.8-25.4, \geq 25.5 \mathrm{~cm}$ in women.

‡CC was divided by sex and into quantitative tertiles: $<26.0,26.0-29.9, \geq 30.0 \mathrm{~cm}$ in men; $<25.0,25.0-28.3, \geq 28.4 \mathrm{~cm}$ in women.

$\mathrm{CC}$, calf circumference; MUAC, mid-upper arm circumference.

(table 3, model IV). The survival curves reveal that higher MUAC and CC are associated with increased survival, with log-rank test $\mathrm{p}=0.0036$ and $\mathrm{p}=0.0160$, respectively (figure 1).

\section{DISCUSSION}

Our study shows that MUAC and CC are inversely related to all-cause mortality in an older Chinese population living in long-term care facilities in Taiwan. This is a prospective cohort study based on a nationally representative sample. Thus, we believe the results from our analysis may be generalisable to the entire Chinese population. In this ageing society, the number of residents living in longterm care facilities is also growing; thus, these findings may also play an increasingly important role in healthcare policies regarding institutionalised elders.

Previous studies have shown that risk factors related to mortality differ in the elder population versus the middle aged or younger populations. ${ }^{18} 19$ While in the younger population, chronic diseases play a more important role in mortality, functional and nutritional status are more closely related to the survival of elders. ${ }^{3}$ Older adults with malnutrition experience poorer health and higher mortality. ${ }^{20} 21$

BMI has long been used to assess nutritional status and frailty, and there is strong evidence to suggest that lower BMI is correlated with higher mortality risk in the elder population. ${ }^{22-26}$ A previous study by Lin and colleagues based on the same patient cohort used in our analysis

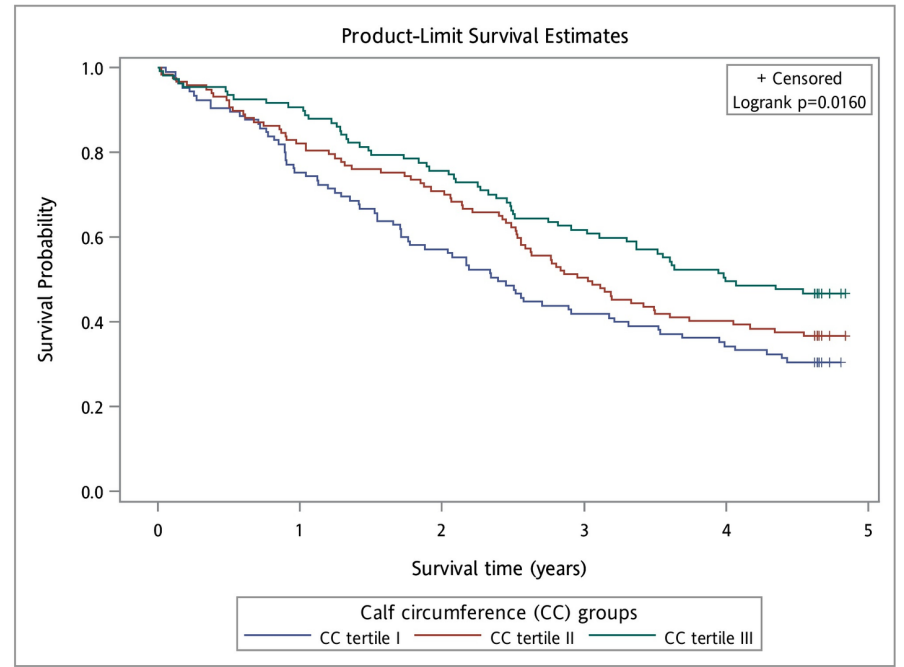

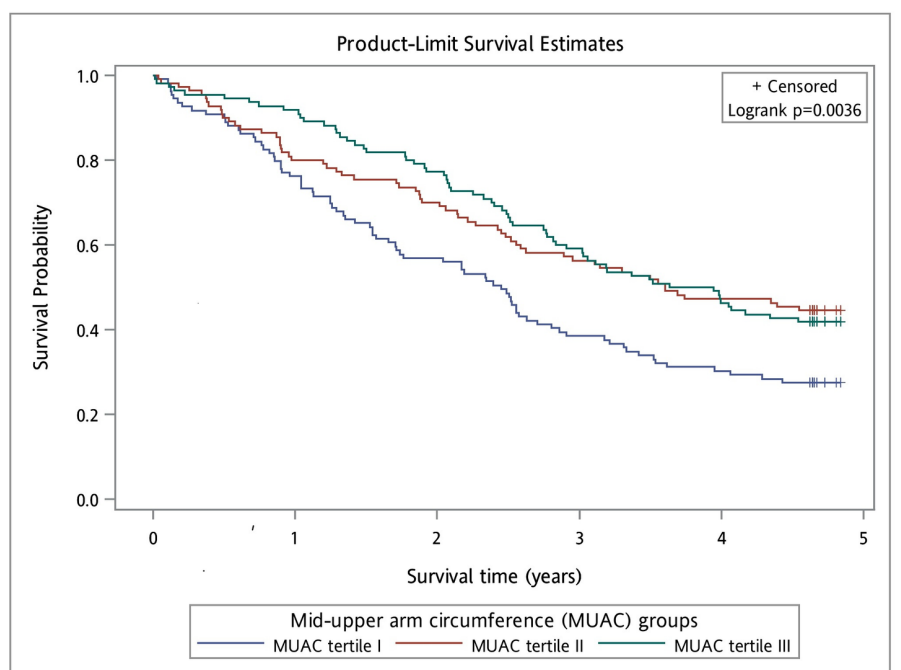

Figure 1 Kaplan-Meier survival curves based on different mid-upper arm circumference (MUAC) and calf circumference (CC) tertiles. Left figure shows the association between MUAC tertiles and risk of all-cause mortality. Right figure shows the association between CC tertiles and risk of all-cause mortality. 
demonstrated a similar relationship between BMI and mortality. ${ }^{5}$ However, it is often difficult to accurately measure the height and weight of frail elders due to deformity or disability of the subjects and limited resources of the researchers. ${ }^{19}$

Measuring MUAC and CC are easier and more cost-effective than measuring height and weight in the older population, and several studies have been done comparing the use of MUAC and CC versus BMI in predicting mortality in the elderly. Many of them have shown that MUAC can be a reliable (if not better) alternative to $\mathrm{BMI}$ in predicting mortality. ${ }^{527-33}$ Wijnhoven et al found that low MUAC is a stronger predictor for mortality than BMI and CC. ${ }^{31}$ Also, a recent study by Mramba et al published in 2017 showed that MUAC performs better than BMI among school age children. ${ }^{34}$ A study analysing community-dwelling older adults in Japan found that MUAC was an independent risk factor for 2-year mortality. ${ }^{35} \mathrm{~A}$ British study of adults age 65 years and over showed a $15 \%$ reduction in all-cause mortality in 15 -year follow-up with every $3.3 \mathrm{~cm}$ increase in MUAC. ${ }^{36}$ A Dutch study concluded a HR of mortality of 1.79 (95\% CI 1.48 to 2.16) per $1 \mathrm{SD}$ decrease in MUAC in men and HR of mortality of 2.26 (95\% CI 1.71 to 3.00$)$ per 1 SD decrease in MUAC in women. ${ }^{31}$

Similarly, several studies have been done comparing calf circumference (CC) and nutritional status or mortality. Portero-McLellan $e t a l$, as well as several other authors, demonstrated a positive correlation between $\mathrm{CC}$ and nutritional status and suggested the potential usefulness of CC in assessing nutritional status. ${ }^{38}$ Lin and colleagues found decreased CC to be the most significant marker of malnutrition in elders age 65 years and above. ${ }^{39}$ Our study and other previous studies showed a significant positive correlation between CC and serum albumin level as well as MUAC and serum albumin level. Serum albumin level is often used to determine current nutritional status. We can conclude that both MUAC and $\mathrm{CC}$ are positively correlated with nutritional status and, like BMI, may be useful markers for assessing mortality risk.

Consistent with numerous previous studies, our research on a Chinese population in Taiwan shows that lower MUAC and CC are correlated with higher mortality. ${ }^{31}$ Most of the earlier studies looking at the relationship between MUAC and CC and mortality were done in European, African and South Asian populations; thus, our Chinese-based prospective cohort study can serve to further strengthen the evidence for use of MUAC and CC in predicting mortality in the elder population.

\section{Limitations}

Our study included two major limitations. First, this study was confined to residents of long-term care facilities; thus, generalisation of our results to the community-dwelling population, indigenous Taiwanese or the rural population, for example, should be made with caution. Second, we have attempted to adjust our results for several confounders including age, sex, cigarette smoking, alcohol use, betel nut chewing, KPSS score, albumin level, HTN and DM. However, there may certainly be additional confounding variables we have not identified here.

\section{CONCLUSION}

Our study showed that both MUAC and CC are inversely associated with all-cause mortality in older adults living in long-term care facilities in Taiwan. The findings may have significant public health implications as the number of institutionalised older adults is steadily increasing in most developed countries. Clinicians and healthcare providers should regularly screen these elder residents using MUAC and CC if BMI cannot be obtained accurately. Further studies evaluating the community-dwelling population, indigenous Taiwanese and/or the rural population should be conducted to verify our findings and confirm the generalisability of our results.

\section{Author affiliations}

${ }^{1}$ Department of Family Medicine, Brown University Warren Alpert Medical School, Providence, Rhode Island, USA

${ }^{2} \mathrm{NH}$ Dartmouth Family Medicine Residency, Concord Hospital, Concord, New Hampshire, USA

${ }^{3}$ Department of Family Medicine, Providence Community Health Centers, Providence, Rhode Island, USA

${ }^{4}$ Department of Family Medicine, China Medical University Hospital, Taichung, Taiwan

${ }^{5}$ Department of Medical Research, China Medical University Hospital, Taichung, Taiwan

${ }^{6}$ Department of Family Medicine, Rural Medical Partners, Grand Forks, North Dakota, USA

${ }^{7}$ Department of Social Medicine, College of Medicine, China Medical University, Taichung, Taiwan

${ }^{8}$ Department of Family Medicine, College of Medicine, China Medical University, Taichung, Taiwan

Contributors C-HW and AL'H wrote the manuscript. W-YL had full access to all the data in the study and keeps the integrity of the data. C-IL, C-PT and W-YL did the statistical analysis and took responsibility for the accuracy of the data analysis. C-HW, AL'H, C-IL, C-PT and W-YL interpreted the findings. All authors contributed to the study design, provided inputs, expertise and critical review of the manuscript and read and approved the manuscript.

Funding This study was financially supported by grants from the Ministry of Health and Welfare, Taiwan (MOHW107-TDU-B-121-123004), Department of Health, Executive Yuan, Taiwan (DOH92-TD-1024), National Science Council of Taiwan (NSC 93-2314-B-039-031), China Medical University Hospital (DMR-93-021, DMR-93078, and DMR-96-061).

Competing interests None declared.

Patient consent Not required.

Ethics approval This study was approved by the Institutional Review Board of China Medical University Hospital (IRB \# DMR91-IRB-071).

Provenance and peer review Not commissioned; externally peer reviewed.

Data sharing statement Extra data is available by emailing the Corresponding author (wylin@mail.cmu.edu.tw)

Open Access This is an Open Access article distributed in accordance with the Creative Commons Attribution Non Commercial (CC BY-NC 4.0) license, which permits others to distribute, remix, adapt, build upon this work non-commercially, and license their derivative works on different terms, provided the original work is properly cited and the use is non-commercial. See: http://creativecommons.org/ licenses/by-nc/4.0/ 
(c) Article author(s) (or their employer(s) unless otherwise stated in the text of the article) 2018. All rights reserved. No commercial use is permitted unless otherwise expressly granted.

\section{REFERENCES}

1. WHO. Nutrition for older persons. http://www.who.int/nutrition/ topics/ageing/en/ (accessed 3 Dec 2017).

2. WHO. Global health and aging. $2011 \mathrm{http}: / /$ www.who.int/ageing/ publications/global_health.pdf

3. Gu D, He J, Duan X, et al. Body weight and mortality among men and women in China. JAMA 2006;295:776-83.

4. Adegbija O, Hoy WE, Dong B, et al. Body mass index and waist circumference as predictors of all-cause mortality in an Aboriginal Australian community. Obes Res Clin Pract 2017;11:19-26.

5. Lin WY, Albu J, Liu CS, et al. Larger body mass index and waist circumference are associated with lower mortality in Chinese longterm care facility residents. J Am Geriatr Soc 2010;58:2092-8.

6. Cook Z, Kirk S, Lawrenson S, et al. Use of BMI in the assessment of undernutrition in older subjects: reflecting on practice. Proc Nutr Soc 2005;64:313-7.

7. Allison DB, Zhu SK, Plankey M, et al. Differential associations of body mass index and adiposity with all-cause mortality among men in the first and second National Health and Nutrition Examination Surveys (NHANES I and NHANES II) follow-up studies. Int J Obes Relat Metab Disord 2002;26:410-6.

8. Wannamethee SG, Shaper AG, Lennon L, et al. Decreased muscle mass and increased central adiposity are independently related to mortality in older men. Am J Clin Nutr 2007;86:1339-46.

9. Zhu S, Heo M, Plankey M, et al. Associations of body mass index and anthropometric indicators of fat mass and fat free mass with allcause mortality among women in the first and second national health and nutrition examination surveys follow-up studies. Ann Epidemiol 2003;13:286-93.

10. Mason C, Craig CL, Katzmarzyk PT. Influence of central and extremity circumferences on all-cause mortality in men and women. Obesity 2008;16:2690-5.

11. Bonnefoy M, Jauffret M, Kostka T, et al. Usefulness of calf circumference measurement in assessing the nutritional state of hospitalized elderly people. Gerontology 2002;48:162-9.

12. Kaiser MJ, Bauer JM, Ramsch C, et al. Validation of the mini nutritional assessment short-form (MNA-SF): a practical tool for identification of nutritional status. J Nutr Health Aging 2009;13:782-8.

13. Tsai AC, Chang TL. The effectiveness of BMI, calf circumference and mid-arm circumference in predicting subsequent mortality risk in elderly Taiwanese. Br J Nutr 2011;105:275-81.

14. Centers for Disease Control. The national health and nutrition examination survey (NHANES) anthropometry procedures manual (revised), 2004

15. Karnofsky DA, Burchenal JH. IM CM, ed. The clinical evaluation of chemotherapeutic agents in cancer. 196. New York, NY: Columbia University Press, 1949.

16. Lee ET, Go OT, Ot G. Survival analysis in public health research. Annu Rev Public Health 1997;18:105-34.

17. Ghali WA, Quan H, Brant R, et al. Comparison of 2 methods for calculating adjusted survival curves from proportional hazards models. JAMA 2001;286:1494-7.

18. Cevenini E, Cotichini R, Stazi MA, et al. Health status and 6 years survival of 552 90+ Italian sib-ships recruited within the EU Project GEHA (GEnetics of Healthy Ageing). Age 2014;36:949-66.

19. Gueresi P, Miglio R, Cevenini E, et al. Arm measurements as determinants of further survival in centenarians. Exp Gerontol 2014;58:230-4

20. Brownie S. Why are elderly individuals at risk of nutritional deficiency? Int J Nurs Pract 2006;12:110-8.

21. Sahyoun NR, Jacques PF, Dallal G, et al. Use of albumin as a predictor of mortality in community dwelling and institutionalized elderly populations. J Clin Epidemiol 1996;49:981-8.
22. Corrada MM, Kawas CH, Mozaffar F, et al. Association of body mass index and weight change with all-cause mortality in the elderly. $A m \mathrm{~J}$ Epidemiol 2006;163:938-49.

23. Breeze E, Clarke R, Shipley MJ, et al. Cause-specific mortality in old age in relation to body mass index in middle age and in old age: follow-up of the Whitehall cohort of male civil servants. Int $J$ Epidemiol 2006;35:169-78.

24. Flegal KM, Graubard BI, Williamson DF, et al. Impact of smoking and preexisting illness on estimates of the fractions of deaths associated with underweight, overweight, and obesity in the US population. Am $J$ Epidemiol 2007;166:975-82.

25. Dey DK, Rothenberg E, Sundh V, et al. Height and body weight in the elderly. I. A 25-year longitudinal study of a population aged 70 to 95 years. Eur J Clin Nutr 1999;53:905-14.

26. Thinggaard $M$, Jacobsen $R$, Jeune $B$, et al. Is the relationship between $\mathrm{BMI}$ and mortality increasingly $U$-shaped with advancing age? A 10-year follow-up of persons aged 70-95 years. J Gerontol A Biol Sci Med Sci 2010;65:526-31.

27. Grellety E, Krause LK, Shams Eldin M, et al. Comparison of weightfor-height and mid-upper arm circumference (MUAC) in a therapeutic feeding programme in South Sudan: is MUAC alone a sufficient criterion for admission of children at high risk of mortality? Public Health Nutr 2015;18:2575-81.

28. Chen $\mathrm{Y}, \mathrm{Ge} \mathrm{W}, \mathrm{Parvez} \mathrm{F}$, et al. A prospective study of arm circumference and risk of death in Bangladesh. Int $\mathrm{J}$ Epidemiol 2014:43:1187-96.

29. de Hollander EL, Bemelmans WJ, de Groot LC. Associations between changes in anthropometric measures and mortality in old age: a role for mid-upper arm circumference? J Am Med Dir Assoc 2013;14:187-93.

30. Rasmussen J, Andersen A, Fisker AB, et al. Mid-upper-armcircumference and mid-upper-arm circumference z-score: the best predictor of mortality? Eur J Clin Nutr 2012;66:998-1003.

31. Wijnhoven HA, van Bokhorst-de van der Schueren MA, Heymans $\mathrm{MW}$, et al. Low mid-upper arm circumference, calf circumference, and body mass index and mortality in older persons. J Gerontol $A$ Biol Sci Med Sci 2010;65:1107-14.

32. Berkley J, Mwangi I, Griffiths K, et al. Assessment of severe malnutrition among hospitalized children in rural Kenya: comparison of weight for height and mid upper arm circumference. JAMA 2005;294:591-7.

33. Powell-Tuck J, Hennessy EM. A comparison of mid upper arm circumference, body mass index and weight loss as indices of undernutrition in acutely hospitalized patients. Clin Nutr 2003;22:307-12.

34. Mramba L, Ngari M, Mwangome M, et al. A growth reference for mid upper arm circumference for age among school age children and adolescents, and validation for mortality: growth curve construction and longitudinal cohort study. BMJ 2017;358:j3423.

35. Enoki H, Kuzuya M, Masuda Y, et al. Anthropometric measurements of mid-upper arm as a mortality predictor for community-dwelling Japanese elderly: the Nagoya Longitudinal Study of Frail Elderly (NLS-FE). Clin Nutr 2007;26:597-604.

36. Bates CJ, Hamer M, Mishra GD. A study of relationships between bone-related vitamins and minerals, related risk markers, and subsequent mortality in older British people: the national diet and nutrition survey of people aged 65 years and over. Osteoporos Int 2012;23:457-66

37. Portero-McLellan KC, Staudt C, Silva FR, et al. The use of calf circumference measurement as an anthropometric tool to monitor nutritional status in elderly inpatients. J Nutr Health Aging 2010;14:266-70.

38. Abd-El-Gawad WM, Abou-Hashem RM, El Maraghy MO, et al. The validity of Geriatric Nutrition Risk Index: simple tool for prediction of nutritional-related complication of hospitalized elderly patients. Comparison with Mini Nutritional Assessment. Clin Nutr 2014;33:1108-16.

39. Lin SJ, Hwang SJ, Liu CY, et al. The relationship between nutritional status and physical function, admission frequency, length of hospital stay, and mortality in old people living in long-term care facilities. $J$ Nurs Res 2012;20:110-21. 